\title{
Assessing The Impacts of Wet Treatment On Leaching Toxicity of Municipal Solid Waste Incineration Bottom Ash
}

\section{Yonghao Zhu}

Zhejiang University of Technology College of Mechanical Engineering

Yanjun Hu ( $\nabla$ huyanjun@zjut.edu.cn )

Zhejiang University of Technology College of Mechanical Engineering

Qianqian Guo

Zhejiang University of Technology College of Mechanical Engineering

\section{Lingqin Zhao}

Zhejiang University of Technology College of Mechanical Engineering

\section{Bin Xu}

Shanghai Urban Planning and Design Research Institute

\section{Research Article}

Keywords: Municipal solid waste incineration bottom ash, Batch test, Standard column up-flow test, Simulate rainfall down-flow test, Leaching behavior, heavy metal

Posted Date: August 3rd, 2021

DOI: https://doi.org/10.21203/rs.3.rs-638582/v1

License: (c) (i) This work is licensed under a Creative Commons Attribution 4.0 International License. Read Full License 


\section{Abstract}

Wet-treatment is usually employed to recover metals from bottom ash (BA). However, its effectiveness on regulating the leaching behavior of $\mathrm{BA}$ and minimizing environmental impact is still unquantified when $\mathrm{BA}$ is used as engineering materials. This study investigated the leaching behavior of targeted pollutants including $\mathrm{Cu}, \mathrm{Zn}, \mathrm{Ni} \mathrm{SO}_{4}{ }^{2-}$ and $\mathrm{Cl}^{-}$in fresh bottom ash (FBA) and treated bottom ash (TBA) using batch, standard column up-flow leaching and simulated rainfall down-flow leaching tests. It was firstly noted by the batch leaching that the potential ecological risk of MSWI bottom ash could not be ignore during its reutilization, and wet treatment enabled reduce the leaching concentration of $\mathrm{Cu}, \mathrm{Zn}, \mathrm{Cl}^{-}$and $\mathrm{SO}_{4}{ }^{2-}$ by $7.1 \%, 33.8 \%, 46.3 \%$ and $18.9 \%$, respectively. The leaching concentrations of the targeted ions in FBA are generally higher than those of TBA. Furthermore, when BA was applied in water dynamic system such as rainfall environment, its toxicity leaching should be paid more attention onto the early leaching stage with a very high water dissolved salts release, such as $\mathrm{Cl}^{-}$and $\mathrm{SO}_{4}{ }^{2-}$. The leaching concentration of $\mathrm{Cu}$ particularly exceeded the limit value before $L / S=1$. Meanwhile, it was also found that the leaching of $\mathrm{SO}_{4}{ }^{2-}, \mathrm{Ni}, \mathrm{Cu}$ and $\mathrm{Zn}$ in water dynamic system were directly proportionate to the liquid-to-solid $(\mathrm{L} / \mathrm{S})$ ratio. The leaching concentration of the pollutants obtained from the simulate rainfall down-flow tests was usually 4-6 times higher than those from the standard up-flow column when at the same ratio of liquid and solid.

\section{Introduction}

Many countries suffer from the surge of municipal solid waste (MSW) generation due to the increasing consumption level and rapid urbanization (Barisa et al. 2015). To counter this issue, municipal solid waste incineration (MSWI) has become a viable alternative due to its effectiveness in reducing the volume up to $90 \%$ and the mass up to $70 \%$ of solid waste, while at the same time producing energy and destroying organic pollutants (Del Valle-Zermeño et al., 2014; Sabbas et al., 2003). Most solid residues of MSWI remains as bottom ash (BA), which accounts for $80-85 \%$ of the total ash residues (Wiles 1996). It brings an impetus to the safe disposal, or preferably, reutilization of BA. The reutilization of BA in road pavement, glasses and ceramics, adsorbent for dyes, and aggregate in concrete are considered safer as they put the bottom ash in a state of chemical stability (Del Valle-Zermeño et al., 2014; Jurič et al., 2006; Keulen et al., 2016; Luo et al., 2017). Nevertheless, MSWI BA is relatively rich in heavy metals and salts such as $\mathrm{Cu}, \mathrm{Zn}, \mathrm{Ni}, \mathrm{Cr}, \mathrm{Pb}, \mathrm{Cl}^{-}$, and $\mathrm{SO}_{4}{ }^{2-}$. The biggest challenge for $\mathrm{BA}$ safe disposal and reutilization was reported (Yin et al. 2018). One of the main concerns is the possibility of material leaching when exposed to rainwater, which could lead to the contamination of nearby sensitive recipients such as water bodies, groundwater systems, as well as fauna and flora (Shih and Ma 2011). Therefore, pre-treatment processes were usually employed to reduce the leaching of heavy metals and dissolved salt from reutilized BA. In southern China, the combination of wet treatment technologies using only water for separating and washing such as wet eddy current separator, jig, and wet shaker are often used to extract metals from bottom ash. Detailed information about wet treatment process of BA in China has been provided in our previous work (Hu et al. 2021). 
In the last few decades, various leaching testing methods were developed and standardized in order to evaluate leaching behavior of certain materials from solid waste and their by-products when exposed to water (Kosson et al. 2002). The leaching tests are typically conducted by either batch equilibrium or column tests (Lopez Meza et al. 2008). In general, the batch leaching test is done in a static container operated for a fixed time (about 24-48h) and under certain controlled conditions ( $\mathrm{pH}$ or L/S) (Butera et al., 2015; Lopez Meza et al., 2008). This test is able to provide an estimation on the leaching availability of a certain composition, but not on leachate release kinetics under dynamic conditions (Grathwohl and Susset, 2009; López Meza et al., 2010). To obtain appropriate description of leaching characteristics in water dynamic system, standardized up-flow column tests are chosen, due to its ability to predict leaching behavior over extended periods of time (Kalbe et al., 2008; Roussat et al., 2008). This test is too restricted to simulate the of specific utilization scenarios, but available to determine the basic leaching characteristics of granular materials in equilibrium with the leachate as a function of liquid-to-solid (L/S) ratio (Butera et al. 2015). This test usually employ a column packed with the solid material and deionized water as extractant is then flowed through it, following the requirements of standardized column leaching test according to CEN TS1405-2017 or EPA-1314. However, this still does not reflect the field-scale conditions, where BA is leached and rinsed by slightly acidic rainwater with $\mathrm{pH}$ of around 5 . Many studies showed that $\mathrm{pH}$ is one of the most important factors that controls the leaching of both inorganic and organic material from solid phase into solution (Kosson et al., 2014; Luo et al., 2019). Hence, as an important environmental factor, the influence of the rainwater leaching due to rainfall acidity on fieldscale leachate should be studied. Another factor not considered in the standard column up-flow leaching test is the compaction of BA applied in road construction. Therefore, the leaching results obtained from the standardized column leaching test were different from practical application due to the differences in $\mathrm{pH}$ and compaction. Standardized up-flow columns also use the saturated flow condition with constant flow rate, while the field-scale utilization of BA in construction works is more likely to experience intermittent down-flow conditions with varying flow rates. It is therefore important to understand the similarities and disparity between the various types of leaching tests to provide better tools for environmental evaluation. While field conditions are unlikely to be exactly duplicated in a laboratory, column leaching tests seem to be the best fit to reflect the field-scale application of BA.

In this study, the leachability of MSWI bottom ash before and after wet treatment was investigated using batch leaching, standardized column up-flow leaching, and the simulated rainfall down-flow leaching tests. The leaching concentration of the targeted ions $\left(\mathrm{Cu}, \mathrm{Zn}, \mathrm{Ni} \mathrm{Cl}^{-}\right.$and $\left.\mathrm{SO}_{4}{ }^{2-}\right)$ were compared with the limit value of surface water of Class $\mathrm{V}$ in China, in order to evaluate their environmental impact. The obtained results could be used to assess the leaching characteristics of the targeted pollutants when reuse $B A$ as engineering materials.

\section{Materials And Methods}

\subsection{Materials}


MSW BA samples were collected from a MSW incineration plant in Shanghai. The grate furnace incinerator operates between $850{ }^{\circ} \mathrm{C}$ to $1000{ }^{\circ} \mathrm{C}$ with a capacity of 750 tons/day. The samples were classified into fresh bottom ash (FBA) and the treated bottom ash (TBA) after wet treatment. FBA refers to a mixture of grate ash, grate sifting, boiler ash, and economizer ash. After incineration, water quenching and water washing were used to recycle metals from FBA and additionally make the resulted bottom ash usable as engineering materials. FBA and TBA samples were sieved to obtain samples with particles size less than $5 \mathrm{~mm}$. Large particles such as ceramics, metal, and glass were manually separated. X-ray fluorescence (XRF) was used to measure the chemical composition of major elements in the samples, and the results are presented in Table 1. The results revealed that the most abundant elements, present as oxides, were as following: $\mathrm{SiO}_{2}$ (>30 wt\%), $\mathrm{CaO}$ (>30 wt\%), $\mathrm{Al}_{2} \mathrm{O}_{3}(>8 \mathrm{wt} \%$ ), and $\mathrm{Fe}_{2} \mathrm{O}_{3}(>6 \mathrm{wt} \%)$. Other than the listed oxides, it is also necessary to pay attention to the heavy metal elements such as $\mathrm{Zn}, \mathrm{Cu}$ and $\mathrm{Ni}$ because of their potential leaching toxicity.

Table 1 Chemical composition of MSWI bottom ashes

\begin{tabular}{|lccccccccc|}
\hline $\begin{array}{l}\text { Chemical } \\
\text { composition }\end{array}$ & $\mathrm{SiO}_{2}$ & $\mathrm{CaO}$ & $\mathrm{Fe}_{2} \mathrm{O}_{3}$ & $\mathrm{Al}_{2} \mathrm{O}_{3}$ & $\mathrm{SO}_{3}$ & $\mathrm{Cl}$ & $\mathrm{ZnO}$ & $\mathrm{CuO}$ & $\mathrm{NiO}$ \\
\hline FBA (wt\%) & 32.23 & 31.63 & 6.27 & 8.38 & 2.76 & 1.90 & 0.579 & 0.209 & 0.0369 \\
\hline TBA (wt\%) & 34.03 & 25.87 & 10.07 & 8.88 & 2.39 & 1.48 & 0.867 & 0.282 & 0.0324 \\
\hline
\end{tabular}

\subsection{Experimental Methods}

\subsubsection{Batch leaching test}

The leaching toxicity tests of the two kinds of materials described in Sect. 2.1 were performed using HJ557-2009 leaching test method. The analytical procedure is as follows: bottom ash samples with a dry basis weight of $100 \mathrm{~g}$ was weighed, then mixed with deionized water with the liquid-solid ratios of 10 $(\mathrm{L} / \mathrm{kg})$. The mixture was then placed in sealed bottles and shaken. The mixing process was done using a mechanical shaker set at $110 \pm 10 \mathrm{rpm}$, for 8 hours. The leachates were then left to settle in the bottles for 16 hours. After that, all leachates were filtered through $0.45 \mu \mathrm{m}$ polypropylene membrane filters and stored at $4{ }^{\circ} \mathrm{C}$ for further analyses.

\subsubsection{Standardized column leaching test}

The percolation column tests were performed in Plexiglas columns with the height of $40 \mathrm{~cm}$ and the inner diameter of $5 \mathrm{~cm}$, based on the specifications of the standard method CEN/TS 14405, 2017. The bottom of the columns was equipped with perforated plates. The columns were closed with threaded connection and stuffed with box packing. A $2.5 \mathrm{~cm}$ thin layer of non-reactive quartz sand was placed in the top and bottom sections of the column. TBA was packed into the columns under light tamping with a plastic rod to level the material between layers. The experiment setting is depicted in Fig. $1 \mathrm{a}$. 
Before starting the test, the filled columns were saturated with deionized water and left for three days in order to equilibrate the system. After the equilibration, the column test is initiated by starting the pump again to flow water at a rate of around $12 \mathrm{~mL} / \mathrm{h}$. Each run was conducted until $10 \mathrm{~L}$ of deionized water has been flowed through the column, giving an L/S ration of $10 \mathrm{~L} / \mathrm{kg}$. During the test, seven kinds of distinct leachate were collected at different cumulative $L / S$ ratios including $0.1,0.2,0.5,1,2,5$, and 10 $\mathrm{L} / \mathrm{kg}$ of dry BA. The eluates were collected in bottles covered with film in order to minimize the effects of carbonation prior to further analysis.

\subsubsection{Simulated rainfall down-flow leaching test}

The experiment setting for rainwater leaching test is illustrated in Fig. 1b. The plexiglass column has an inner diameter of $9 \mathrm{~cm}$ and length of $75 \mathrm{~cm}$. It is filled with sand and BA layers similar to the standard column up-flow test with different amount of BA such as depicted in Fig. 1b. The liquid used was a solution with $\mathrm{pH}=5$, which was adjusted using appropriate volumes of deionized water and nitric acid to simulate acid rain water. A constant flow rate of $3.18 \mathrm{ml} / \mathrm{min}$ simulating the maximum 24-hour rainfall rate in southern China was maintained by the peristaltic pump. The column test was done for 72 hours each run. A threshold of $85 \%$ of the minimum compaction specification requirements for road pavement (JTGF10, 2006) was adopted.

Prior to the experiment, the column was rinsed with acid solution and then cleaned with deionized water. Two filtration layers of acid-washed quartz sand were then placed at the top and bottom of the sample layer. The sample was then placed and compacted every $5 \mathrm{~cm}$, to $85 \%$ of the minimum compaction specification requirements for road pavement (JTGF10-2006). Then the soil surface was roughened, and the next filling was continued. The total loading height of slag was $50 \mathrm{~cm}$. Depending on the material, the total weight of slag was between $5 \mathrm{~kg}$ and $6 \mathrm{~kg}$. Before the experiment, the soil column was saturated slowly from top to bottom with leaching liquid, before the peristaltic pump was started. The leaching solution was collected at the lower outlet at certain time intervals. All leachates obtained from the tests were preserved with $\mathrm{HNO}_{3}\left(2 \%\right.$ volume), sealed, and stored at $4{ }^{\circ} \mathrm{C}$ before analysis for dissolved elements.

To quantify the pollution level of leachate, the release data were compared with the limit value of surface water of Class V in China (GB3838-2002), which corresponds to agricultural and general surface water bodies.

\section{Results And Discussion}

\subsection{Leachability of BA by batch leaching tests}

The obtained results from batch leaching tests of FBA and TBA based on the standard ${ }^{\mathrm{HJ} 557-2010}$ are presented in Fig. 2. It can be observed that the leaching concentrations of all the targeted ions exceeded the limit of the surface water class $\mathrm{V}$. Zn had the highest concentration among the heavy metal eluates, which was up to 210 and $139 \mathrm{mg} / \mathrm{L}$ for FBA and TBA, respectively. However, the leaching concentration of the targeted heavy metals was noticed to be far lower than the targeted soluble salts. $\mathrm{Cu}$ and $\mathrm{Ni}$ had 
leaching concentrations below $10 \mathrm{mg} / \mathrm{L}$, while $\mathrm{Cl}^{-}$and $\mathrm{SO}_{4}{ }^{2-}$ had much higher concentrations as shown in Fig. 2. The high concentration of soluble salts could be attributed to that these two ions are mainly released from waste through biological and chemical processes, as reported in various studies (Luo et al., 2019b; Mandal et al., 2017). Observed from the obtained results, it could be interpreted that the main soluble compounds in $\mathrm{BA}$ comprised of $\mathrm{SO}_{4}{ }^{2}$ and $\mathrm{Cl}^{-}$, which is in good agreement with previous studies by Del Valle-Zermeño et al., 2014 and Ito et al., 2008. Furthermore, the wet treatment appears to significantly lowered the leachability of $\mathrm{Cu}, \mathrm{Zn}, \mathrm{Cl}^{-}$and $\mathrm{SO}_{4}{ }^{2-}$ from bottom ash by $7.1 \%, 33.8 \%, 46.3 \%$ and $18.9 \%$, respectively. The only anomaly is observed with $\mathrm{Ni}$, which content in the leachate increased by a factor of about 0.56 after water washing. In general, the results of these experiments indicate that wet treatment could improve the suitability of MSWI bottom ash for utilization in road construction.

\subsection{Leachability of BA by Standardized column leaching test}

The liquid-to-solid (L/S) ratio could influence the chemical form of elements in BA and the leachability of heavy metals, and could be utilized to increase the mass transfer rate of dissolvable elements between the solid and liquid phases. Therefore, the L/S ratio strongly affects the leaching behavior of dissolvable elements, especially for those processes that controlled by solubility (Del Valle-Zermeño et al., 2014; Luo et al., 2019b). The leaching concentrations obtained over the L/S ratio range are affected by the solubility, availability, and rate of mass transfer from solid to liquid. Standardized up-flow column tests are available to determine the basic leaching characteristics of granular materials in equilibrium with the leachate as a function of $\mathrm{L} / \mathrm{S}$ ratio.

Figure 3 presents the variation of $\mathrm{pH}$ and conductivity of the $\mathrm{BA}$ under a function of L/S ratio for FBA and TBA in standard-column leaching test. The variation of $\mathrm{pH}$ is found to be inconspicuous for all L/S ratios, for all samples being around $7-8$. In addition, the $\mathrm{pH}$ values in this study are smaller than those reported in a few other studies (López Meza et al., 2010; Meima and Comans, 1997). This might be linked to the differences in $\mathrm{CaO}$ and $\mathrm{MgO}$ mineral contents in solid residues and the dissolution rates of these minerals in aqueous solutions (Komonweeraket et al., 2015; Gitari et al., 2009). Another possible reason is the uptake of atmospheric $\mathrm{CO}_{2}$ by the initial alkaline material due to the exposure to weather, which leads to a lower $\mathrm{pH}$ and the precipitation of calcite. The conductivity of leachate with lower $\mathrm{L} / \mathrm{S}$ are inclined to be higher for both FBA and TBA, which may be a consequence of the 3-day pre-equilibration period at the beginning of the tests. It implies that the leaching of contaminants from BA mostly occurs in the early stages of leaching. Conductivity in the leachate in the FBA $(1.824 \mathrm{mS} / \mathrm{cm}$ at $\mathrm{L} / \mathrm{S}=0.1)$ is higher than that in the TBA $(0.767 \mathrm{mS} / \mathrm{cm}$ at $\mathrm{L} / \mathrm{S}=0.1)$. This result indicates that FBA washes out more ions into the leachate, which confirms the effectiveness of the water washing process of BA. Moreover, water can easily remove organic matter and soluble ions from BA (Lin et al. 2011).

Figure 4. shows the concentrations and mass release of $\mathrm{SO}_{4}{ }^{2-}, \mathrm{Cl}^{-}, \mathrm{Cu}, \mathrm{Zn}$ and $\mathrm{Ni}$ as a function of $\mathrm{L} / \mathrm{S}$ ratio for standard-column leaching test. The elemental concentrations generally decrease with the increase of $\mathrm{L} / \mathrm{S}$ ratio. $\mathrm{Cl}^{-}$concentration is extremely high after equilibration at the beginning of the up- 
flow percolation tests, with approximately $3720 \mathrm{mg} / \mathrm{L}$ and $11820 \mathrm{mg} / \mathrm{L}$ for TBA and FBA, respectively. Meanwhile, $\mathrm{SO}_{4}{ }^{2-}$ leaching level is also found to be high at the beginning leaching stage, with $2020 \mathrm{mg} / \mathrm{L}$ and $3960 \mathrm{mg} / \mathrm{L}$ for TBA and FBA, respectively. This raises a concern because large amounts of soluble salts in the leachate would deteriorate the environment when it is applied. As shown in Fig. $4 \mathrm{Cl}^{-}$ evidently exceeds the limit value before $L / S=1$, while $\mathrm{SO}_{4}{ }^{2-}$ exceeds the limit value almost in the entire leaching process. This phenomenon correlates the high leaching of the dissolved salt in the BA. Moreover, it is compounded by the lengthy equilibrium period at the beginning of the up-flow percolation tests. The leaching concentration of $\mathrm{Cu}$ also exceeds the limit value, with the highest concentration of $7.92 \mathrm{mg} / \mathrm{L}$. $\mathrm{Zn}$ concentration generally falls below the limit value, with only a data point exceeding the limit. The above results indicate that the adverse effect of $\mathrm{Cu}$ and $\mathrm{Zn}$ leaching behavior could be ignored after $\mathrm{L} / \mathrm{S}=1$, with all concentrations below the safe value.

Solubility-controlled leaching is characterized by an approximately linear dependence of cumulative release on the L/S ratio (Sabbas et al. 2003). It can be observed in Fig. 4, where the release of $\mathrm{SO}_{4}{ }^{2-}, \mathrm{Ni}$, $\mathrm{Cu}(\mathrm{TBA})$ and $\mathrm{Zn}(\mathrm{TBA})$ are directly proportionate to the L/S ratio. While concentrations of other ions such as $\mathrm{Cl}^{-}, \mathrm{Cu}(\mathrm{FBA})$ and $\mathrm{Zn}(\mathrm{FBA})$ are proportionate to $\mathrm{L} / \mathrm{S}$ ratio until certain points where they remain constant.

Comparing the obtained results on the leachability of different types of BA, an obvious difference between FBA and TBA is noted. The leaching concentration of the targeted pollutants in FBA is generally higher than that of TBA. Especially for $\mathrm{SO}_{4}{ }^{2-}$ and $\mathrm{Cl}^{-}$, their leachability in FBA is far higher than that in TBA.

The most obvious disparity regarding leaching concentration between FBA and TBA could be noted in $\mathrm{SO}_{4}{ }^{2-}$ and $\mathrm{Cl}^{-}$, indicating that water can easily remove these soluble ions from $\mathrm{BA}$. A similar conclusion was also reported by Lin et. al. (Lin et al. 2011). Furthermore, the leaching concentration of heavy metals in the bottom ash after wet treatment is below environmental quality standards for surface water in GB3838-2002. This proved the effectiveness of pollutants purification for BA using wet treatment. On the other hand, there is a possibility that $\mathrm{Cu}$ and $\mathrm{Zn}$ in the TBA formed stable and unleachable chemical structure based on the different comparisons of initial content in table 1 and leachate concentration for two materials. Some studies reported that the complexation of dissolved organic matter toward metals is likely to facilitate the leaching of Cu from MSWI BA (Van Zomeren and Comans 2004). While Meima and Comans (Meima and Comans, 1997) found that the solubility of $\mathrm{Zn}$ is mainly controlled by calcium zincate in alkaline conditions. For the column test of FBA, a significant increase of $\mathrm{Zn}$ leaching concentration is still observed for the terminate leachate, which implies that the solid and liquid phase equilibriums might have not been reached even after $\mathrm{L} / \mathrm{S}=10$ during the leaching period. The results appear to validate the conclusion that the leaching of heavy metals in BA is a very slow process influenced by the contact time, the type of heavy metal leaching, and MSWI-BA particle size under different conditions (Zhao and Zhu 2019). According to previous studies, a close correlation between 
batch and column leaching tests could be established for a better understanding of leachability of heavy metals (Delay et al., 2007; Lopez Meza et al., 2008).

\subsection{Leachability of BA by Simulated rainfall down-flow leaching test}

The flow rate is designed according to the recorded maximum South China's natural rainfall intensity of $0.5 \mathrm{~mm} / \mathrm{min}$. Accordingly, the flow rate of peristaltic pump is set to be $3.18 \mathrm{ml} / \mathrm{min}$, under which the amount of water flowed through the sample per hour is equivalent to 9.7 days of water exposure to continuous natural rainfall. The leaching experiments were conducted for FBA and TBA, and the leachability of $\mathrm{Cl}^{-}, \mathrm{Cu}$, and $\mathrm{Zn}$ were detected for their high concentrations in the leachate as found in the standard tests. Figure 5 shows the leaching concentrations of $\mathrm{Cl}^{-}, \mathrm{Cu}^{2+}$ and $\mathrm{Zn}^{2+}$ along time.

According to the leaching characteristics of the targeted pollutants shown in Fig. 5, the leaching process of $\mathrm{Cl}^{-}, \mathrm{Cu}^{2+}$ and $\mathrm{Zn}^{2+}$ could be divided into three stages, viz. a continuous and rapid decrease, a slow decrease, and a stable leaching in the 1st-7th month, 7th-13th month, and 13th-24th month, respectively. The dissolution or desorption of ash matrix's surfaces may result in a high leaching concentration of ions during the first stage of simulated rainfall, as reported by Dijkstra et al. (Dijkstra et al., 2006). The maximum leaching concentrations of $\mathrm{Cl}^{-}, \mathrm{Cu}^{2+}$ and $\mathrm{Zn}^{2+}$ from FBA are $19700,17.9$ and $2.79 \mathrm{mg} / \mathrm{L}$, respectively. The high leaching concentration of $\mathrm{Cl}^{-}$confirms the finding that rainfall is the major factor in decreasing the high $\mathrm{Cl}^{-}$content of BA via dissolution and dilution (Chen et al. 2016). Wet treatment exhibits a positive effect on reducing the leaching concentrations of $\mathrm{Cu}^{2+}$ in the TBA. The leaching concentration of $\mathrm{Cu}^{2+}$ in FBA is found to be above the safe limits at the whole duration of the experiment. After washing, however, the $\mathrm{Cu}^{2+}$ leaching levels falls below the safe limit for a very short period at the beginning of experiment. The comparison also shows that wet treatment can improve the environmental friendliness by reutilizing MSWI bottom ash. The final values of the $\mathrm{Cl}^{-}, \mathrm{Cu}^{2+}$ and $\mathrm{Zn}^{2+}$ release from FBA is $3.5,11.8$ and 11.3 times of those of TBA, respectively.

\subsection{Comparison among various leaching tests}

The experimental conditions for rainwater leaching test are more appropriate for simulating field scale due to the consideration of $\mathrm{pH}$ value and compaction, while the factors are not considered in the standard column up-flow tests. Figure 6 presents the different leaching concentrations at the beginning and the end stage of all types of columns leaching tests. It should be noted that the initial leachate was sampled at the same L/S ratio of 0.1 . The results indicates that the leaching values of the targeted pollutants using simulated rainfall down-flow leaching test are usually 4-6 times of standard column up-flow tests. Especially, the comparison of $\mathrm{Cu}$ is most prominent with a factor of 35.

Despite the leaching differences, some similar conclusions could still be drawn. Firstly, the targeted heavy metals in this study follow a cationic leaching pattern. Luo et. al. reported that the concentrations of leached elements decrease with the increased pH values of the rainwater solution's (Luo et al. 2019b). Secondly, the compaction in the simulated rainfall down-flow leaching tests affects the reaction time 
between water and ash particles. A compacted BA layer can prolong the retention time of rainwater, thus increasing the leaching concentrations. The differences in leaching concentrations are important for evaluating environmental characteristics of BA during its reutilization.

Figure 7 shows the comparison between cumulative leaching of the targeted pollutants from the simulated rainwater down-flow leaching and standardized up-flow column leaching tests. Results of cumulative leaching amounts from standard up-flow column are still lower than that of standard column up-flow tests, except for the leaching mass of $\mathrm{Cu}$ in the FBA. As illustrated by the correlation, it could be deduced the leaching tests method applied has an evident effect on the final assessment of the expected leaching release. For instance, the cumulative release of the two leaching tests is significantly different. The results also give an important information that the initial and final cumulative release of the targeted elements ions are highly consistent in the simulated rainwater rainfall down-flow leaching tests, indicating that the environmental impact of BA is underestimated for standardized column leaching test.

\section{Conclusions}

The toxic leaching characteristics of fresh and treated bottom ash were investigated using batch leaching and standard column up-flow leaching and simulated rainfall down-flow leaching tests. $\mathrm{Cu}, \mathrm{Zn}, \mathrm{Ni}^{-} \mathrm{Cl}^{-}$ and $\mathrm{SO}_{4}{ }^{2-}$ were chosen to be the targeted pollutants in this study. The batch leaching results showed that the potential ecological risk of MSWI bottom ash could not be ignore during its reutilization, and wet treatment enabled reduce the leaching concentration of $\mathrm{Cu}, \mathrm{Zn}, \mathrm{Cl}^{-}$and $\mathrm{SO}_{4}{ }^{2-}$ by $7.1 \%, 33.8 \%, 46.3 \%$ and $18.9 \%$, respectively. The leaching concentrations of all the targeted ions exceeded the limits specified in the standard of the surface water class V. Especially, Zn had the highest concentration with 210 and 139 $\mathrm{mg} / \mathrm{L}$ for FBA and TBA, respectively. The results obtained from standard column up-flow leaching indicated that the $\mathrm{Cu} \square \mathrm{Zn} \square \mathrm{Cl}^{-}$and $\mathrm{SO}_{4}{ }^{2-}$ in leachate evidently exceeded limit value before $\mathrm{L} / \mathrm{S}=1$, while the environmental pollution of $\mathrm{Cu}$ and $\mathrm{Zn}$ could be ignored after $\mathrm{L} / \mathrm{S}=1$ for a low extraction toxicity. Based on the results obtained from the two column leaching tests, the leaching concentration and cumulative release amount of the target pollutants in the leachate of FBA was generally higher than that of TBA. Furthermore, this indicated that wet-treatment was appropriately used to improve the environmental friendliness with the resource utilization process of MSWI bottom ash.

\section{Declarations}

Ethics approval and consent to participate: No applicable.

Consent for publication: No applicable.

Availability of data and materials: The datasets generated and analysed during the current study are not publicly available due the nature of this research but are available from the corresponding author on reasonable request. 
Competing interests: The authors declare that they have no competing interests.

Funding: This work was supported by the [Science Foundation of Shanghai Municipal Planning and Design Institute] under Grant [No. A102020254].

Authors' contributions: YH was the project leader, finished the design of the experiment, data analysis, conclusion, and paper writing. YZ was in charge of the sampling of the raw and treated bottom ash, part of heavy metals analysis and other experiments, and paper writing. QG was in charge of data analysis and language improvement. LZ did the measurement of heavy metals in bottom ash and data analysis. BX was in charge of did the properties of measurement of aggregate and bottom ash. All authors read and approved the final manuscript.

Acknowledgements: The authors want to appreciate the project of the Science Foundation of Shanghai Municipal Planning and Design Institute (Grant No. A102020254), providing financial support for this work.

\section{References}

1. Barisa A, Dzene I, Rosa M, Dobraja K (2015) Waste-to-biomethane concept application: A case study of Valmiera city in Latvia. Environ Clim Technol 15:48-58

2. Butera S, Hyks J, Christensen TH, Astrup TF (2015) Construction and demolition waste: Comparison of standard up-flow column and down-flow lysimeter leaching tests. Waste Manag 43:386-397. https://doi.org/10.1016/j.wasman.2015.04.032

3. CEN (2017) Characterization of waste - Leaching behaviour test - Upflow percolation test (under specified conditions). Eur Stand

4. Chen X, Bi Y, Zhang H, Wang J (2016) Chlorides Removal and Control through Water-washing Process on MSWI Fly Ash. Procedia Environ Sci 31:560-566

5. Del Valle-Zermeño R, Formosa J, Prieto M et al (2014) Pilot-scale road subbase made with granular material formulated with MSWI bottom ash and stabilized APC fly ash: Environmental impact assessment. J Hazard Mater 266:132-140

6. Delay M, Lager T, Schulz HD, Frimmel FH (2007) Comparison of leaching tests to determine and quantify the release of inorganic contaminants in demolition waste. Waste Manag 27:248-255. https://doi.org/10.1016/j.wasman.2006.01.013

7. Dijkstra JJ, Van Der Sloot HA, Comans RNJ (2006) The leaching of major and trace elements from MSWI bottom ash as a function of pH and time. Appl Geochemistry 21:335-351. https://doi.org/10.1016/j.apgeochem.2005.11.003

8. Gitari WM, Fatoba OO, Petrik LF, Vadapalli VRK (2009) Leaching characteristics of selected South African fly ashes: Effect of pH on the release of major and trace species. J Environ Sci Heal - Part A Toxic/Hazardous Subst Environ Eng 44:206-220 
9. Grathwohl P, Susset B (2009) Comparison of percolation to batch and sequential leaching tests: Theory and data. Waste Manag 29:2681-2688

10. Hu Y, Zhao L, Zhu Y et al (2021) The fate of heavy metals and salts during the wet treatment of municipal solid waste incineration bottom ash. Waste Manag 121:33-41

11. Ito R, Dodbiba G, Fujita T, Ahn JW (2008) Removal of insoluble chloride from bottom ash for recycling. Waste Manag 28:1317-1323

12. Jurič B, Hanžič L, Ilić R, Samec N (2006) Utilization of municipal solid waste bottom ash and recycled aggregate in concrete. Waste Manag 26:1436-1442

13. Kalbe U, Berger W, Eckardt J, Simon FG (2008) Evaluation of leaching and extraction procedures for soil and waste. Waste Manag 28:1027-1038

14. Keulen A, Van Zomeren A, Harpe P et al (2016) High performance of treated and washed MSWI bottom ash granulates as natural aggregate replacement within earth-moist concrete. Waste Manag 49:83-95. https://doi.org/10.1016/j.wasman.2016.01.010

15. Komonweeraket $\mathrm{K}$, Cetin $\mathrm{B}$, Aydilek AH et al (2015) Effects of $\mathrm{pH}$ on the leaching mechanisms of elements from fly ash mixed soils. Fuel 140:788-802

16. Kosson DS, Garrabrants AC, Delapp R, Sloot HA, Van Der (2014) Chemosphere pH-dependent leaching of constituents of potential concern from concrete materials containing coal combustion fly ash. Chemosphere 103:140-147

17. Kosson DS, Van Der Sloot HA, Sanchez F, Garrabrants AC (2002) An Integrated Framework for Evaluating Leaching in Waste Management and Utilization of Secondary Materials. Environ Eng Sci 19:159-204. https://doi.org/10.1089/109287502760079188

18. Lin YC, Panchangam SC, Wu CH et al (2011) Effects of water washing on removing organic residues in bottom ashes of municipal solid waste incinerators. Chemosphere 82:502-506. https://doi.org/10.1016/j.chemosphere.2010.11.010

19. Lopez Meza S, Garrabrants AC, van der Sloot H, Kosson DS (2008) Comparison of the release of constituents from granular materials under batch and column testing. Waste Manag 28:1853-1867. https://doi.org/10.1016/j.wasman.2007.11.009

20. López Meza S, Kalbe U, Berger W, Simon FG (2010) Effect of contact time on the release of contaminants from granular waste materials during column leaching experiments. Waste Manag 30:565-571. https://doi.org/10.1016/j.wasman.2009.11.022

21. Luo H, Cheng Y, He D, Yang EH (2019a) Review of leaching behavior of municipal solid waste incineration (MSWI) ash. Sci Total Environ 668:90-103

22. Luo H, Cheng Y, He D, Yang EH (2019b) Review of leaching behavior of municipal solid waste incineration (MSWI) ash. Sci Total Environ 668:90-103

23. Luo H, He D, Zhu W et al (2019c) Humic acid-induced formation of tobermorite upon hydrothermal treatment with municipal solid waste incineration bottom ash and its application for efficient removal of $\mathrm{Cu}(\mathrm{II})$ ions. Waste Manag 84:83-90 
24. Luo HL, Chen SH, Lin DF, Cai XR (2017) Use of incinerator bottom ash in open-graded asphalt concrete. Constr Build Mater 149:497-506. https://doi.org/10.1016/j.conbuildmat.2017.05.164

25. Mandal P, Dubey BK, Gupta AK (2017) Review on landfill leachate treatment by electrochemical oxidation: Drawbacks, challenges and future scope. Waste Manag 69:250-273. https://doi.org/10.1016/j.wasman.2017.08.034

26. Meima JA, Comans RNJ (1997) Geochemical modeling of weathering reactions in municipal solid waste incinerator bottom ash. Environ Sci Technol 31:1269-1276

27. Ministry of Communications of the People's Republic of China (2006) Technical specification for construction of highway subgrsdes JTG F10-2006. China Commun Press Beijing

28. National Environmental Protection Administration of the People's Republic of China (2010) Solid waste-Extraction procedure for leaching toxicity-Horizontal vibration method HJ 557-2010. Press China Environ Sci

29. Roussat N, Méhu J, Abdelghafour M, Brula P (2008) Leaching behaviour of hazardous demolition waste. Waste Manag 28:2032-2040

30. Sabbas T, Polettini A, Pomi R et al (2003) Management of municipal solid waste incineration residues. 23:61-88. https://doi.org/10.1016/S0956-053X(02)00161-7

31. Shih $\mathrm{H}$, ching, Ma H wen (2011) Assessing the health risk of reuse of bottom ash in road paving. Chemosphere 82:1556-1562

32. Van Zomeren A, Comans RNJ (2004) Contribution of natural organic matter to copper leaching from municipal solid waste incinerator bottom ash. Environ Sci Technol 38:3927-3932. https://doi.org/10.1021/es035266v

33. Wiles CC (1996) Municipal solid waste combustion ash: State-of-the-knowledge. J Hazard Mater 47:325-344. https://doi.org/10.1016/0304-3894(95)00120-4

34. Yin K, Chan WP, Dou X et al (2018) Cr, Cu, Hg and Ni release from incineration bottom ash during utilization in land reclamation - based on lab-scale batch and column leaching experiments and a modeling study. Chemosphere 197:741-748. https://doi.org/10.1016/j.chemosphere.2018.01.107

35. Zhao Y, Zhu YT (2019) Metals leaching in permeable asphalt pavement with municipal solid waste ash aggregate. Water 11:. https://doi.org/10.3390/w11102186

\section{Figures}




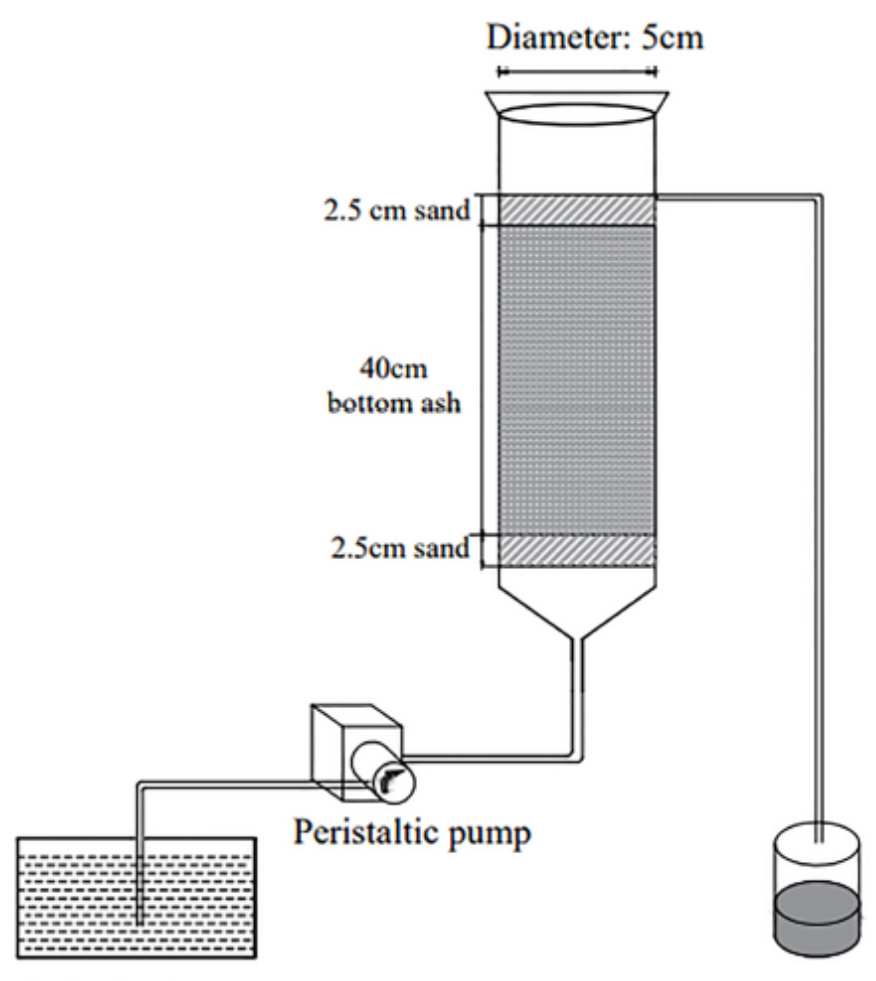

Deionized water

(a)

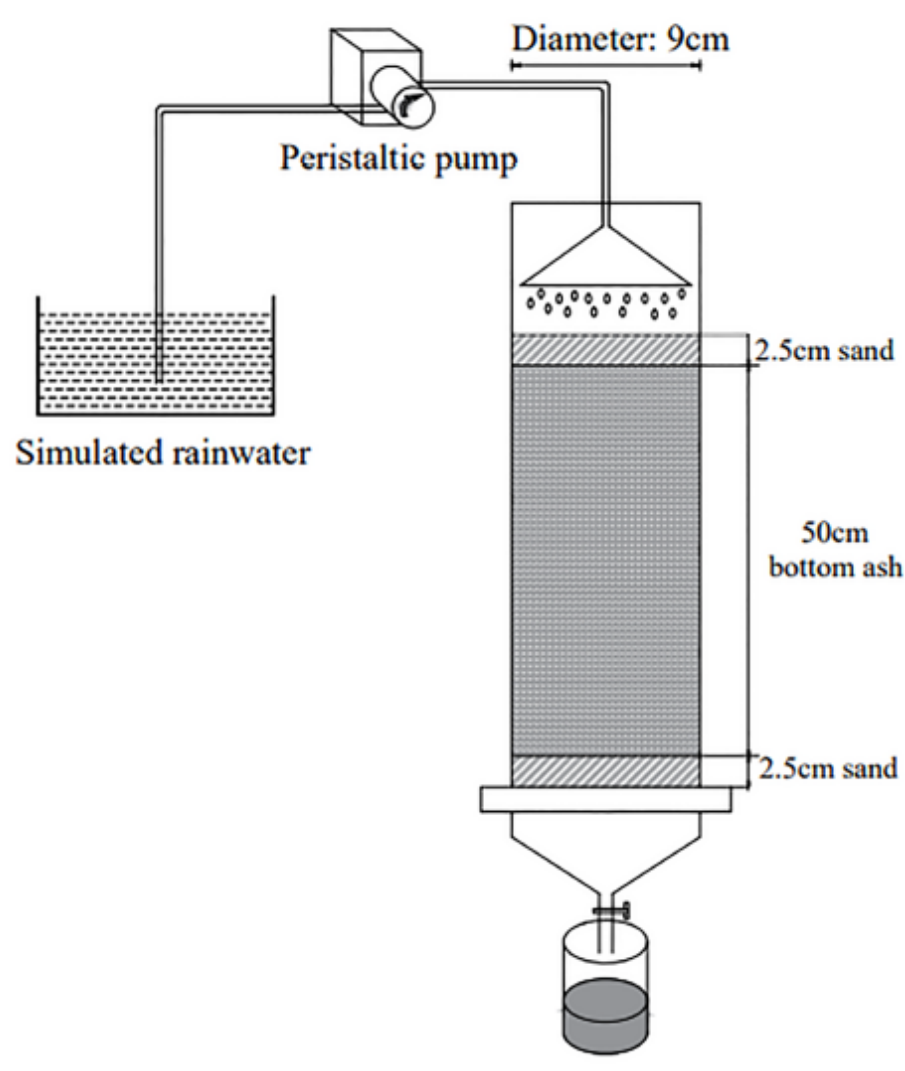

(b)

\section{Figure 1}

A schematic model of the standard column up-flow and simulated rainfall down-flow leaching tests setup 


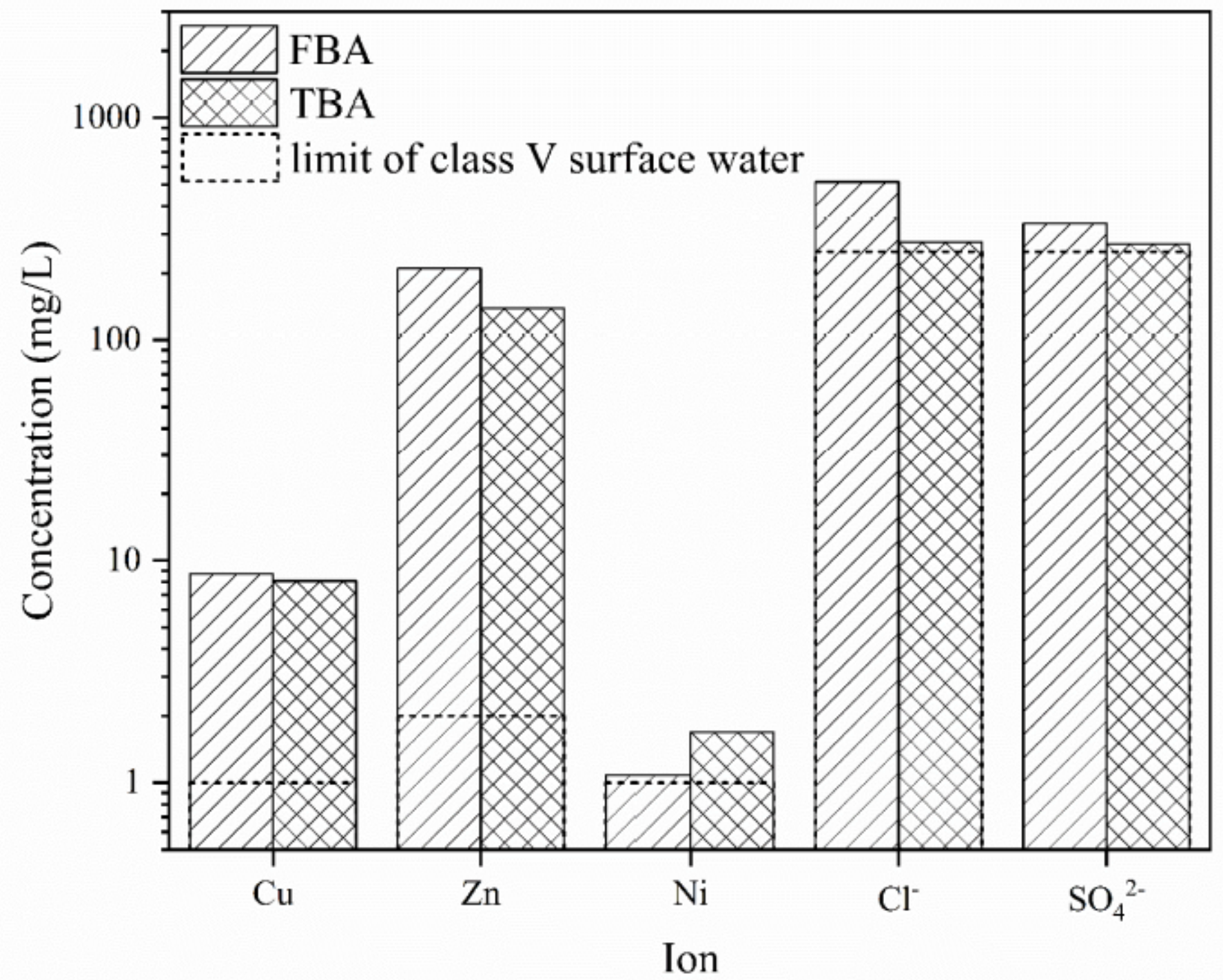

Figure 2

Leaching concentrations of heavy metals and dissolved salt

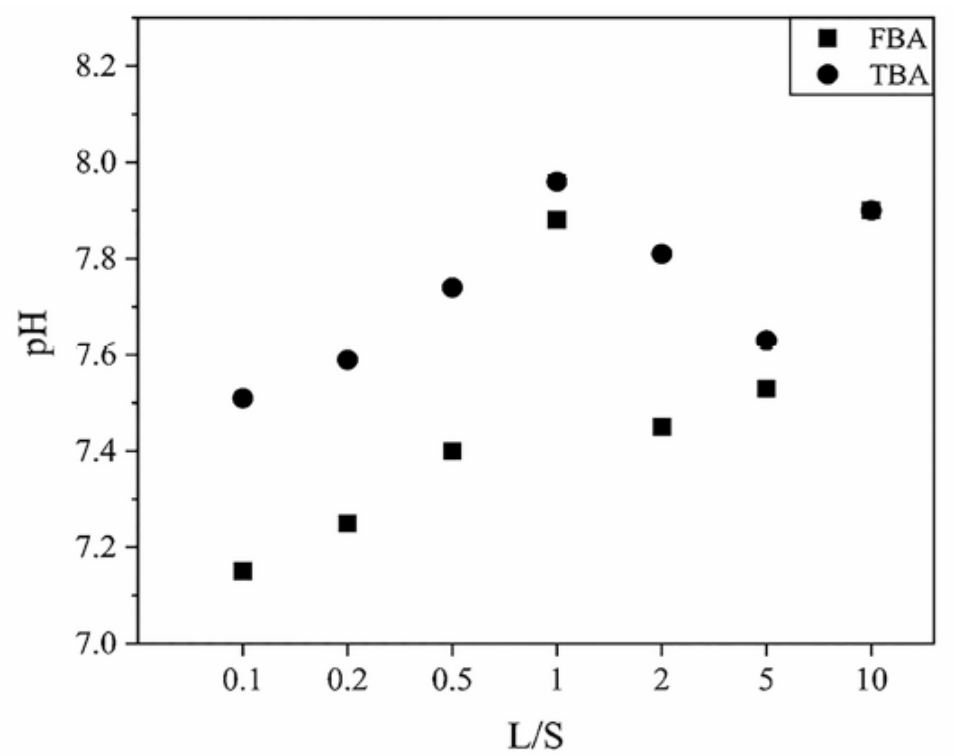

(a)

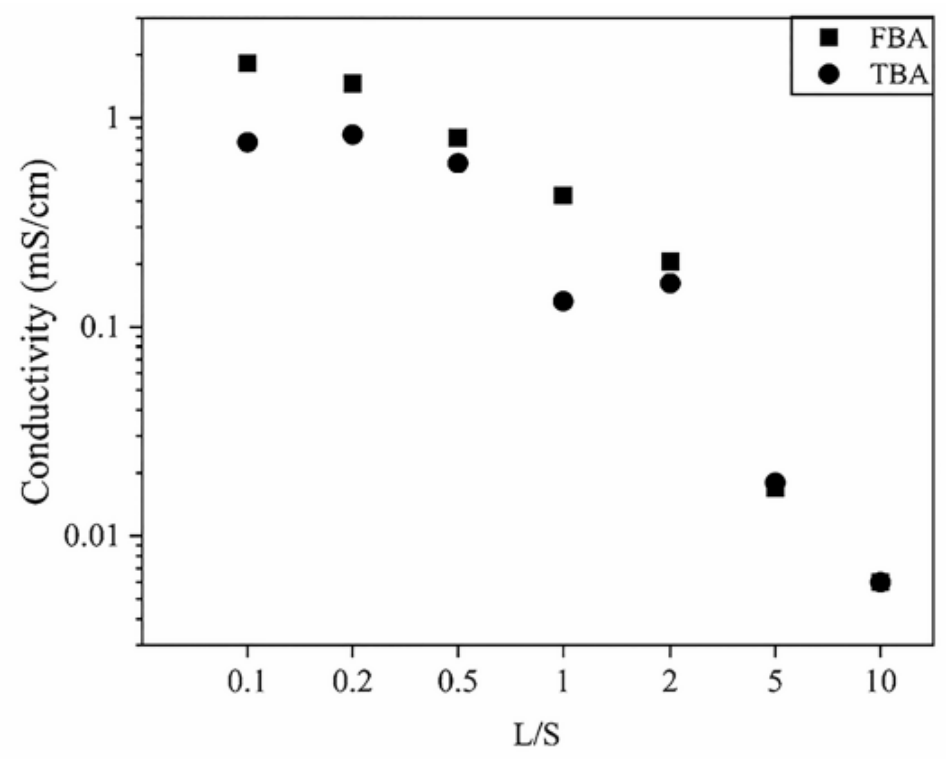

(b) 
Figure 3

Results of $\mathrm{pH}(\mathrm{a})$ and conductivity (b) pattern over L/S ratio from standardized column leaching test
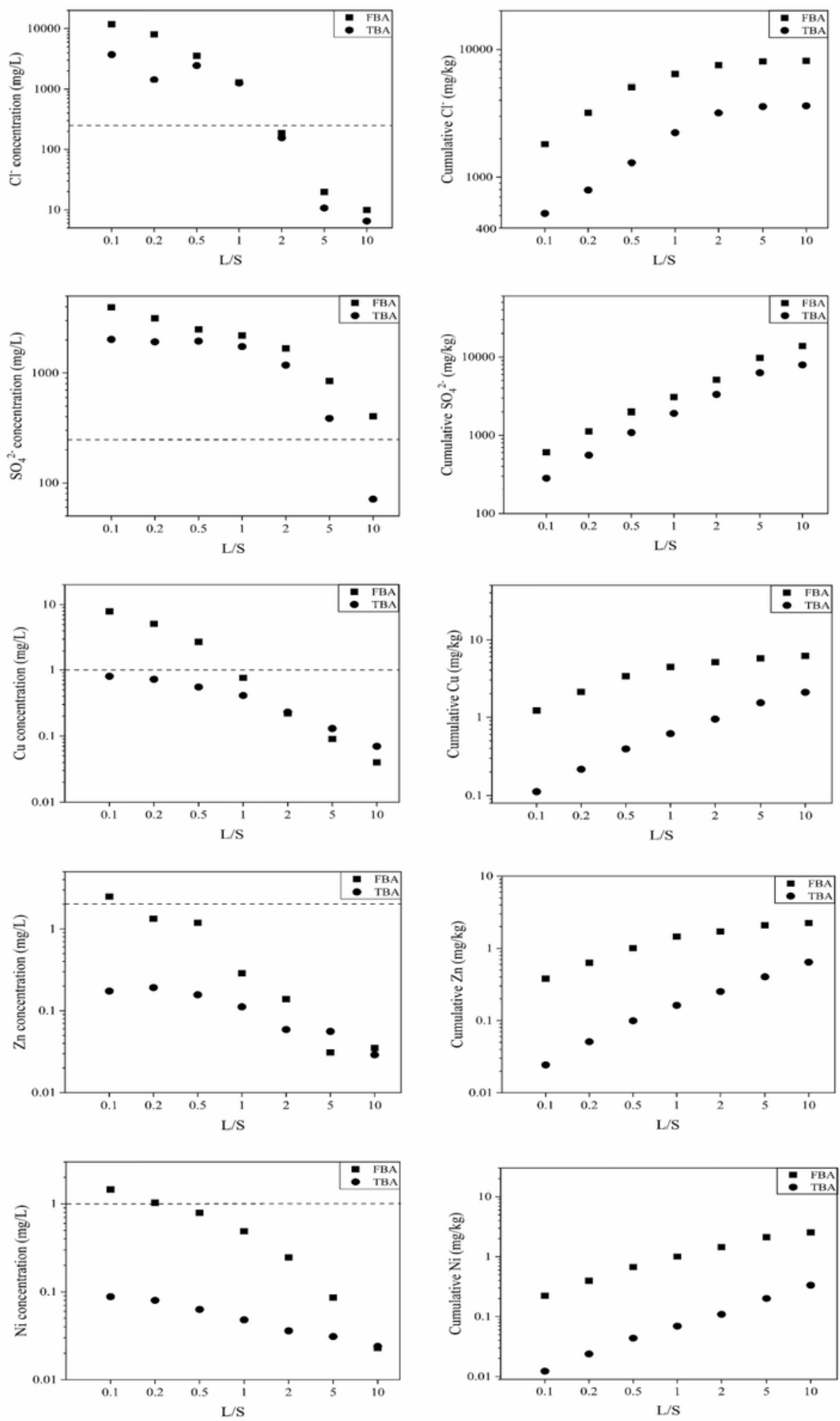

Figure 4

The leachability of $\mathrm{Cl}-, \mathrm{SO} 42-, \mathrm{Cu}, \mathrm{Zn}$ and $\mathrm{Ni}$ from the up-flow percolation tests as a function of L/S ratio 

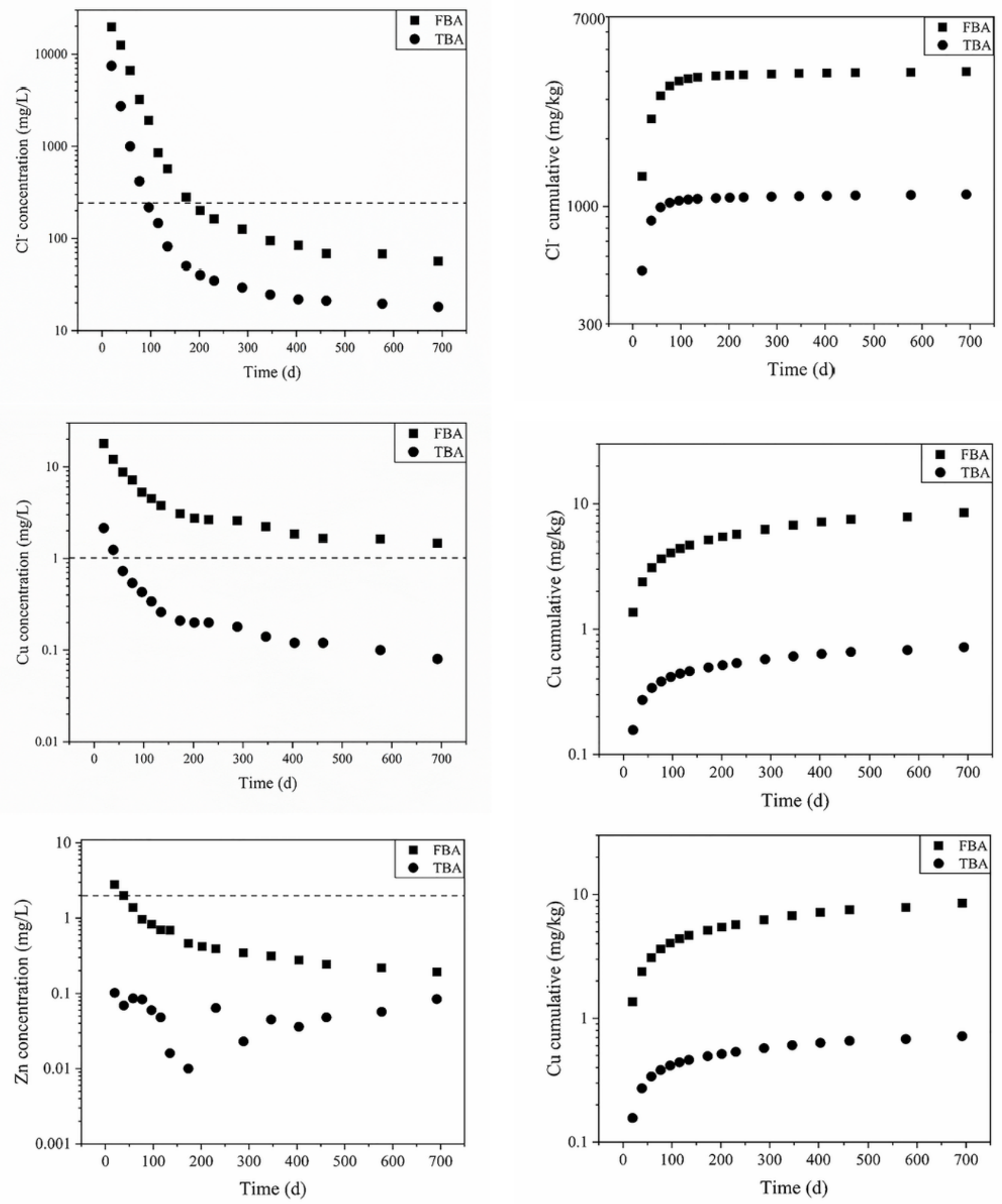

Figure 5

Leaching concentrations of $\mathrm{Cl}-, \mathrm{Cu} 2+$ and $\mathrm{Zn} 2+$ from the simulated rainfall down-flow leaching test along time 


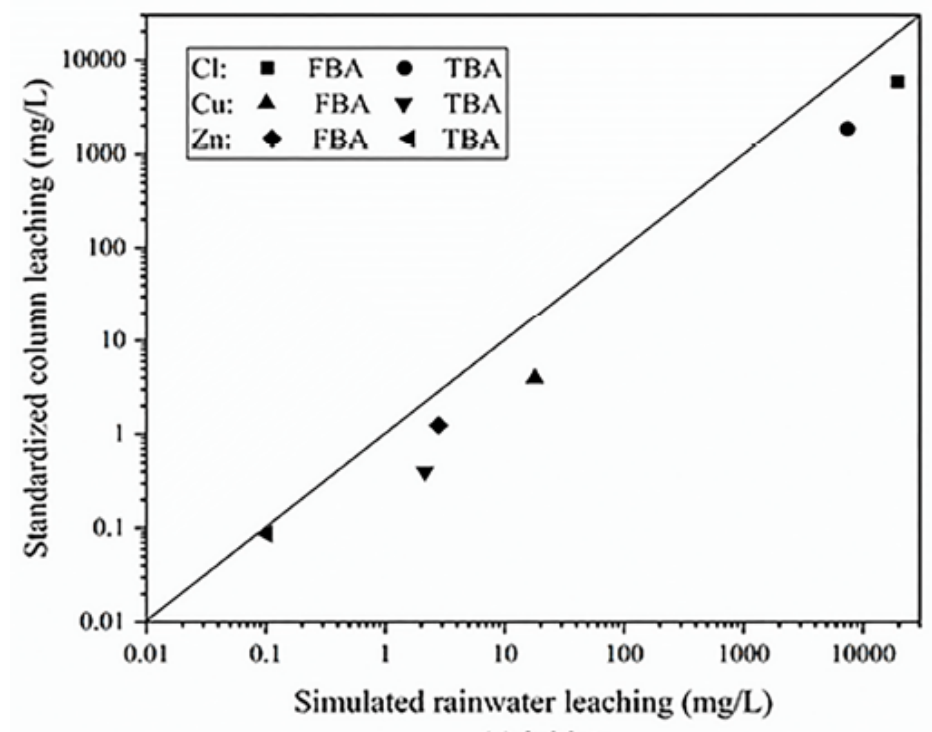

(a) initiate

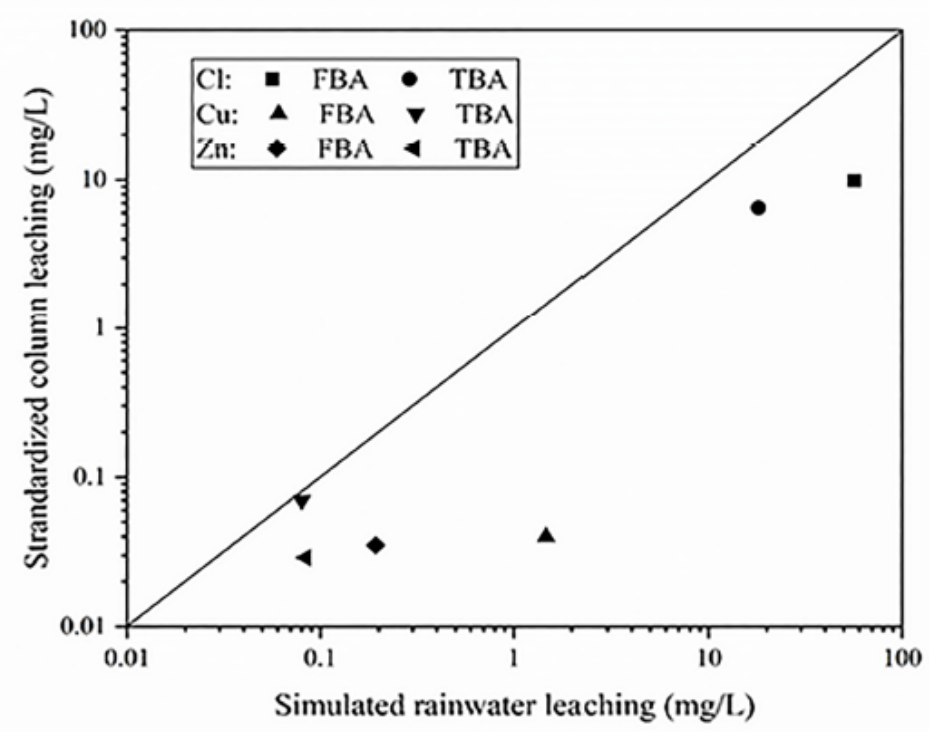

(b) terminate

Figure 6

Leaching concentrations at the beginning and the end stage of leaching tests

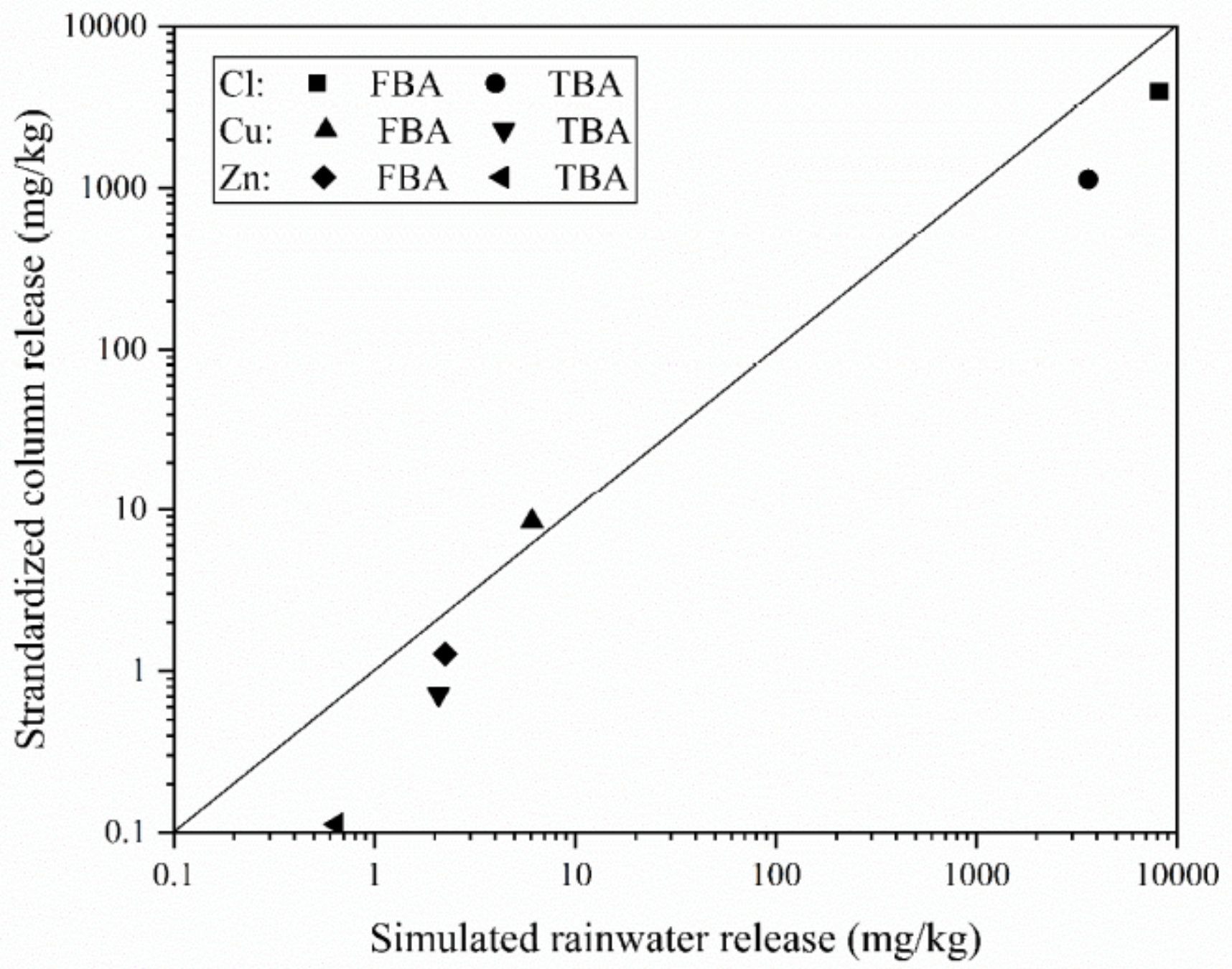


Figure 7

Cumulative leaching of the targeted pollutant from the tests of simulated rainwater leaching and standardized column leaching 